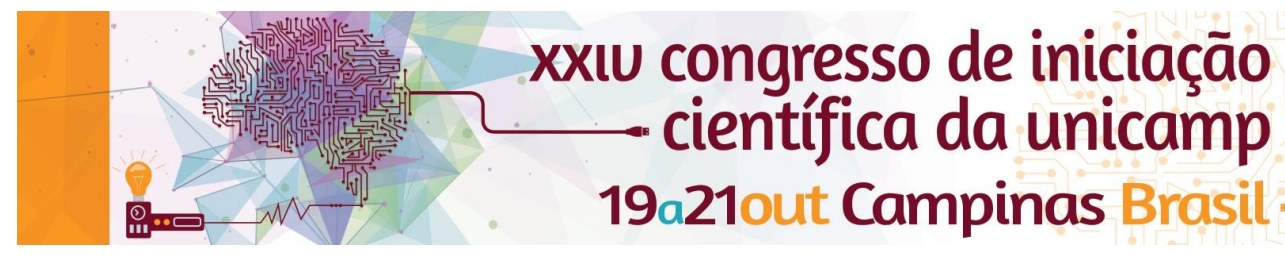

\title{
Absorção de Dois Fótons em Nanomateriais Semicondutores
}

\author{
Leonardo W. T. Barros*, Lázaro A. Padilha
}

\section{Resumo}

Utilizamos a técnica de fotoluminescência excitada por absorção de dois fótons para medirmos a absorção de dois fótons de diferentes amostras de pontos quânticos, todas com um núcleo de CdSe de mesmo diâmetro e com a casca de ZnCdS de diferente espessura. Pudemos testar a influência da variação da espessura da casca na absorção de dois fótons. Os resultados sugerem um aumento de absorção que não segue a escala volumétrica anteriormente observada para os pontos quânticos de CdSe sem casca.

\section{Palavras-chave:}

Óptica não-linear, nanomateriais semicondutores, absorção de dois fótons

\section{Introdução}

Pontos quânticos são pequenas partículas, de tamanho nanométrico, compostas por semicondutores, de forma que elétrons são confinados nas três dimensões. Devido a tal confinamento, esse tipo de nanomaterial tem propriedades óticas e eletrônicas diferentes do que é observado em materiais ordinários. Essas propriedades exclusivas os tornam candidatos para aplicações em diferentes áreas, como biologia e computação. Além disso, pontos quânticos também têm sido pesquisados para servirem na fabricação de células solares e diferentes tipos de dispositivos optoeletrônicos. Recentemente, a manipulação eletrônica da função de onda via engenharia de nanoestruturas tem sido usada para que as propriedades óticas e eletrônicas do material sejam melhor controladas. Neste trabalho, estudamos a influência da espessura da casca na absorção não-linear de amostras de pontos quânticos de CdSe/ZnCdS.

\section{Resultados e Discussão}

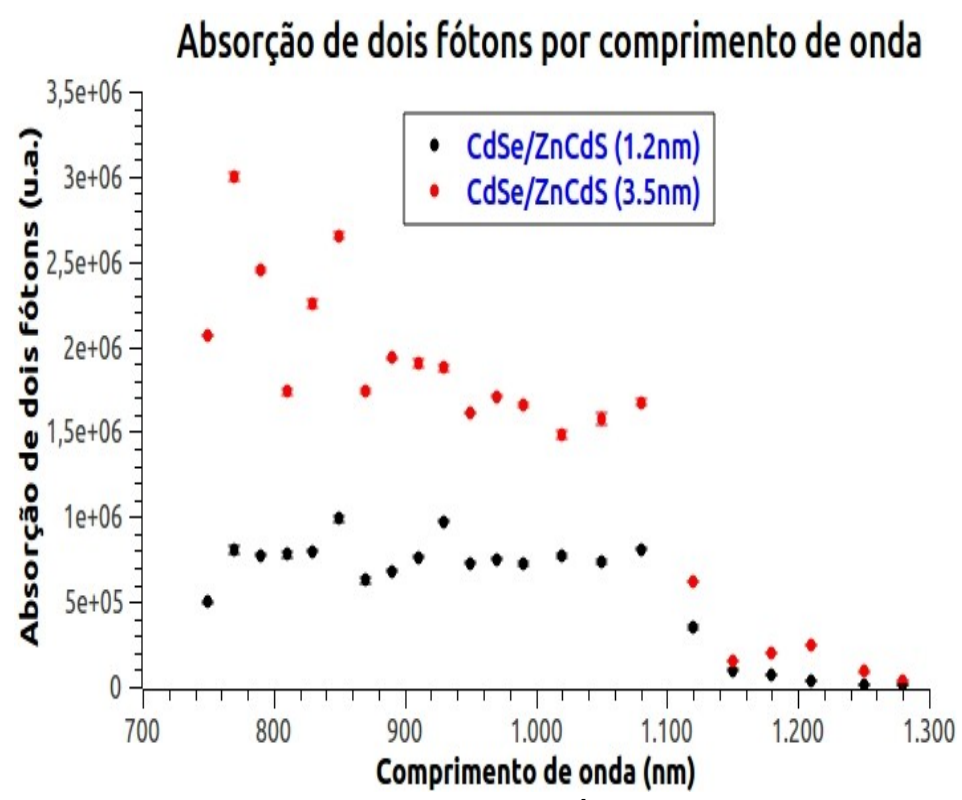

Figura 1. Absorção de dois fótons (em unidades arbitrárias) por comprimento de onda do laser de excitação (em nanômetros).
Usando a técnica de fotoluminescência excitada por absorção de dois fótons, nós medimos o espectro de absorção de dois fótons para amostras com o mesmo diâmetro do núcleo mas diferentes espessuras da casca. As medidas foram realizadas no intervalo 750-1280nm de comprimento de onda do laser de excitação.

Nossos resultados sugerem que, mudando a espessura da casca, é possível mudar a intensidade da absorção de dois fótons no intervalo 750-870nm, o que corresponde ao intervalo de comprimento de onda para a transição por absorção de dois fótons entre 375 - 435 $\mathrm{nm}$. Isso indica a região na qual a casca também absorve e não apenas o núcleo de CdSe. A Figura 1 mostra o gráfico com nossas amostras com espessura de casca de 1.2 e 3.5nm.

\section{Conclusão}

Nossos primeiros resultados mostram que o aumento da absorção de dois fótons com a mudança da espessura da casca não segue a mesma escala volumétrica anteriormente observada para os pontos quânticos de CdSe sem a casca, e modelos teóricos são necessários para explicar tais diferenças.

\section{Agradecimentos}

Agradeço primeiramente ao meu orientador, o Prof.Dr. Lázaro Padilha, pela oportunidade de realizar o meu trabalho, pela confiança dada e pelo longo tempo dedicado ao meu projeto. Agradeço também ao aluno de mestrado Gabriel Nagamine, pelas conversas e conselhos, e aos alunos de graduação Thiago Cardoso, por me auxiliar em meu treinamento, e Ana Gabriela Barbosa, por todo o suporte prestado.

\footnotetext{
1. Fu, J., Molecular Structure - Nonlinear Optical Property relationships for a series of Polymethine and Squaraine molecules. 2006, 15-18.

2. Xu, C.; Webb, W. W., Measurement of two-photon excitation cross sections of molecular fluorophores with data from 690 to $1050 \mathrm{~nm}$. Journal of the Optical Society of America B- Optical Physics 1996, 13 (3), 481-491.

3. Nikolay S. Makarov, Mikhail Drobizhev, and Aleksander Rebane, "Twophoton absorption standards in the 550-1600 nm excitation wavelength range," Opt. Express 16, 4029-4047 (2008)
} 